
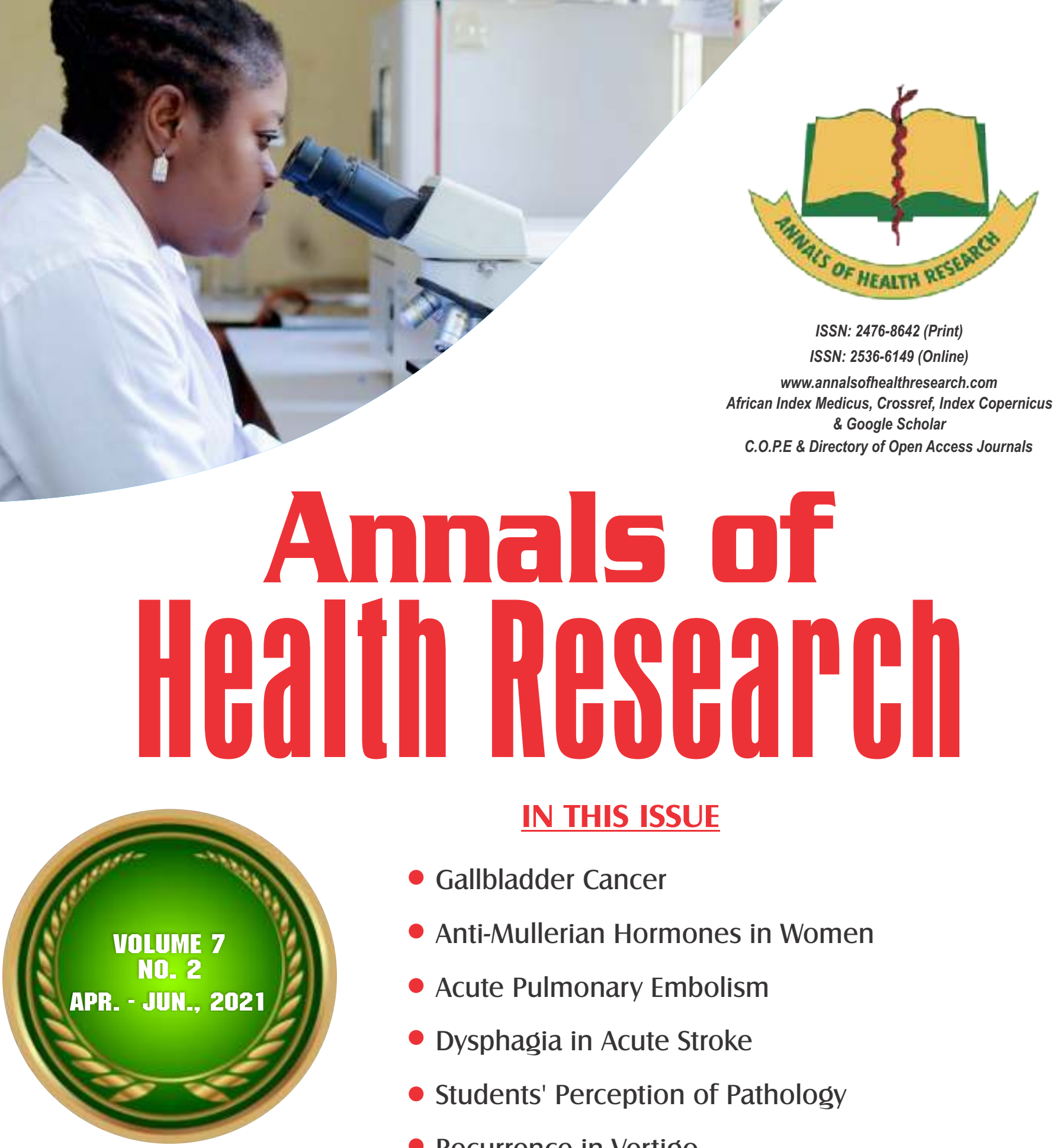

IN THIS ISSUE

- Gallbladder Cancer

- Anti-Mullerian Hormones in Women

- Acute Pulmonary Embolism

- Dysphagia in Acute Stroke

- Students' Perception of Pathology

- Recurrence in Vertigo

- Electroencephalography in Epilepsy

- Health-seeking Behaviour

- Breastfeeding and Nutritional Status

- Osteosarcoma

PUBLISHED BY THE MEDICAL AND DENTAL CONSULTANTS ASSOCIATION OF NIGERIA, OOUTH, SAGAMU, NIGERIA. 


\title{
Relationship between breastfeeding practices and nutritional status of children aged 6-24 months in South-west Nigeria Abolurin $\mathrm{OO}^{* 1}$, Oyelami $\mathrm{OA}^{2}$, Oseni $\mathrm{SB}^{2}$, Akinlosotu $\mathrm{MA}^{3}$, Sodeinde $\mathrm{KJ}^{4}$, Adekoya $\mathrm{AO}^{1}$
}

${ }^{1}$ Department of Paediatrics, Babcock University, Ilishan-Remo, Ogun State, Nigeria ${ }^{2}$ Department of Paediatrics and Child Health, Obafemi Awolowo University, Ile-Ife, Osun State, Nigeria 3Department of Paediatrics, University of Medical Sciences, Ondo, Ondo State, Nigeria ${ }^{4}$ Department of Community Medicine, Babcock University, Ilishan-Remo, Ogun State, Nigeria

*Correspondence: Dr OO Abolurin, Department of Paediatrics, Babcock University, Ilishan-Remo, Ogun State, Nigeria. E-mail: funlyt@yahoo.com; ORCID - https://orcid.org/0000-0001-8651-0113.

\begin{abstract}
Background: Breastfeeding is the ideal form of nutrition for the healthy growth of infants, and it reduces the risk of malnutrition and several childhood morbidities.

Objectives: To assess the breastfeeding practices of mothers and the relationship between these practices and the nutritional status of their children.

Methods: It was a descriptive, hospital-based, cross-sectional study that involved children aged six to 24 months in Ilesa, Osun State, Nigeria. Socio-demographic characteristics and breastfeeding practices were documented, anthropometric measurements were obtained, and nutritional status was determined for the children. Underweight, stunting and wasting were defined as z-score $<-2$ for the weight-for-age, length-for-age and weight-for-length, respectively. A child was taken to be undernourished if any of underweight, stunting or wasting was present.

Results: Fifteen (3.6\%) of the 420 children studied had mixed feeding from birth, while 273 (65.0\%) were exclusively breastfed for six months. Two hundred and sixty-eight (63.8\%) of them were still breastfeeding at the time of the study, while $152(36.2 \%)$ had stopped breastfeeding. Nearly one-quarter (103/420; 24.5\%) of the children were undernourished. A significantly lower proportion of children who had exclusive breastfeeding were undernourished, compared to those who were not exclusively breastfed $(p=0.033)$. Exclusive breastfeeding was independently associated with reduced odds of undernutrition $(\mathrm{OR}=1.62,95 \% \mathrm{CI}=1.02-2.57, \mathrm{p}=0.039)$.
\end{abstract}

Conclusion: Exclusive breastfeeding for six months significantly reduces the risk of undernutrition among young children.

Keywords: Children, Exclusive breastfeeding, Nigeria, Nutritional status, Undernutrition.

\section{Introduction}

Breastfeeding is the ideal form of nutrition for the healthy growth and development of infants.[1]
The World Health Organization (WHO) recommends that infants should be exclusively breastfed during the first six months of life and that breastfeeding is continued until at least two years of age.[1] Breastfeeding has several benefits 
for infants, including reduced risk and severity of malnutrition as well as infections such as diarrhoea, pneumonia and otitis media. ${ }^{2-5]}$

Exclusive breastfeeding (EBF) entails feeding babies breastmilk only for the first six months of life without other foods or drinks. [1, 6] However, mothers frequently introduce water and other water-based drinks or supplements before the age of six months for various reasons. According to the Nigeria Demographic and Health Survey (NDHS 2018), almost all (97\%) Nigerian children were breastfed at some point, with $29 \%$ being exclusively breastfed until the age of six months. ${ }^{[7]}$ The average duration of exclusive breastfeeding among Nigerian children was 2.8 months; with the median duration of any breastfeeding being 18.5 months. ${ }^{[7]}$

Despite having good knowledge of exclusive breastfeeding, many mothers still find it challenging to breastfeed exclusively. This has been attributed to factors such as job conditions (resumption of work), time constraints, inadequate breastmilk/poor lactation, sore or retracted nipples, lack of spousal support and socio-cultural beliefs..8-10] Likewise, factors that have been reported to promote EBF practices among mothers include good family and social support systems, favourable workplace policies and continuous education on the importance of EBF, especially during antenatal care. ${ }^{[9]}$

Breastfeeding helps to prevent childhood undernutrition, which is a major contributor to under-five mortality in developing countries. [1,11] According to the NDHS 2018, about 37\% of Nigerian children under the age of five years are stunted, while about $22 \%$ are underweight and $7 \%$ are wasted. ${ }^{[7]}$ More than half of all deaths in under-five children in developing countries are attributable, either directly or indirectly, to undernutrition. [1, 12, 13] A significantly lower prevalence of stunting and underweight was reported among Malawian infants under six months who were exclusively breastfed, compared with their counterpart who were on mixed feeding. ${ }^{[14]}$ In Bangladeshi children aged 624 months, a significantly lower prevalence of stunting and underweight was also reported among those who had EBF.[15] Similarly, Kenyan children under two years who had not been exclusively breastfed were two times more likely to be underweight than those who had EBF for six months; and that those who had discontinued breastfeeding were four times more likely to be underweight than those who were still breastfeeding.[16] In Nigeria, underweight and stunting were recorded only among infants of mothers who did not practice optimal breastfeeding (which encompassed early initiation of breastfeeding and EBF). ${ }^{[17]}$

Presently, there is a paucity of studies on the relationship between breastfeeding practices and the growth of Nigerian children. Therefore, the present study was carried out to assess the breastfeeding practices of mothers, and the relationship between these practices and undernutrition among their children. The information obtained from the study may help guide mothers to improve their breastfeeding practices, to improve the nutritional status of their children.

\section{Methods}

The study was carried out at the Children's Welfare Clinic (CWC) of the Wesley Guild Hospital (WGH), Ilesa, Osun State, south-west Nigeria between August 2015 and March 2016. The WGH is a unit of the Obafemi Awolowo University Teaching Hospitals Complex (OAUTHC), Ile-Ife, Nigeria. The OAUTHC serves the health needs of the urban and rural communities in Osun State and its neighbouring states in southwest Nigeria. It is a major referral health facility that provides both general and specialist paediatric care for these communities. 
It was a descriptive, cross-sectional study that involved apparently healthy children aged six to 24 months. Children within this age group, who presented at the $\mathrm{CWC}$ of the WGH for a routine check-up, immunization or minor complaints were consecutively recruited (by convenience sampling) for the study with the consent of the parent (s). Children who had features suggestive or confirmed to have sickle cell disease, Human Immunodeficiency Virus (HIV) infection or other acute or chronic diseases (such as malaria or pneumonia) were excluded from the study. A total of four hundred and twenty (420) children were recruited.

\section{Ethical considerations}

Ethical clearance was obtained for the study from the Ethics and Research Committee of the OAUTHC. Written, informed consent was also obtained from the mother of each study participant.

\section{Data collection}

Data collection was done using a pre-tested interviewer-administered questionnaire. The questionnaire was administered by the investigators and research assistants who had been trained on the study protocol. The information obtained included biodata, occupation and level of education of the parents, the practice of exclusive breastfeeding (EBF), and the age at cessation of breastfeeding. The duration of exclusive breastfeeding was defined as the period after birth, during which the infant was given only breastmilk, without water or other supplemental feeds, [1,6] while the total duration of breastfeeding was defined as the entire period (in months) for which the child took breastmilk before the date of recruitment into the study.

Social class was assessed using the classification by Oyedeji, [18] based on the occupation and educational qualifications of both parents. Social classes I and II were classified as high social class, while classes III, IV and V were classified as low social class. Anthropometric measurements (weight and length) were recorded for each child, and nutritional status was assessed. Weight was measured using a Wayster infant weighing scale after removing shoes, clothing and diapers, while the length was measured using an infantometer. Nutritional status was determined by plotting the weight and height measurements on the World Health Organization (WHO) Child Growth Charts, ${ }^{[19]}$ and obtaining z-scores for the weightfor-age, length-for-age and weight-for-length parameters, to assess for underweight, stunting and wasting, respectively. Underweight, stunting and wasting were defined as z-score < 2 for the corresponding parameter. A child was taken to be undernourished if any of underweight, stunting or wasting was present, while the well-nourished children were those who had none of these nutritional abnormalities.

\section{Data analysis}

Data were analysed using the Statistical Package for the Social Sciences (SPSS) version 22.0. Means \pm standard deviations (SD) were computed for continuous variables, while proportions were calculated for discrete variables. Means were compared using the independent samples t-test $(t)$, while the Pearson Chi-Square test $\left(x^{2}\right)$ was used for comparing proportions. Logistic regression analysis (B) was done to determine factors independently associated with undernutrition. Probability (p) values less than 0.05 at a $95 \%$ confidence interval (CI) were accepted as statistically significant.

\section{Results}

A total of 420 children were studied. Table I shows the socio-demographic characteristics of the children. Their ages ranged from 6 to 24 months with a mean of $13.5 \pm 4.7$ months. Sixty-six $(15.7 \%)$ were older than 18 months. More than half $(59.0 \%)$ were males and a majority $(74.2 \%)$ 
belonged to the low social class. Nearly half $(48.8 \%)$ of the mothers had tertiary education.

The duration of receiving 'breastmilk only' ranged from 0-6 months with a mean of $5.1 \pm 1.5$ months. Fifteen $(3.6 \%)$ of the children had mixed feeding from birth, while $273(65.0 \%)$ were exclusively breastfed for six months. Two hundred and sixty-eight $(63.8 \%)$ of the children were still breastfeeding as at the time of the study, while 152 (36.2\%) had been weaned.

Table I: Socio-demographic characteristics of the children and their mothers

\begin{tabular}{llll}
\hline Characteristics & & Frequency & Percentage \\
& & & \\
\hline Age Group & $6-12$ & 196 & 46.7 \\
& $13-18$ & 158 & 37.6 \\
& $>18$ & 66 & 15.7 \\
Sex & Male & 248 & 59.0 \\
& Female & 172 & 41.0 \\
Mother's level & of & & \\
education & No formal & 5 & 1.2 \\
& education & & \\
& Primary & 53 & 12.6 \\
& Secondary & 157 & 37.4 \\
& Tertiary & 205 & 48.8 \\
Social class & Low & 320 & 76.2 \\
& High & 100 & 23.8 \\
\hline
\end{tabular}

Among those who had been weaned, breastfeeding was discontinued at $\leq 12$ months, 13-18 months and $>18$ months among 46 (30.3\%), $102(67.1 \%)$ and $4(2.6 \%)$ children, respectively; none was breastfed till two years. Seventy-two $(26.9 \%)$ of the 268 children who were still breastfeeding were aged between 13-18 months while $7(2.6 \%)$ were older than 18 months. The total duration of breastfeeding ranged from 6 months to 22 months with a mean of $12.1 \pm 3.3$ months; it was $\leq 12$ months in 235 (56.0\%) children, while it was $>12$ months in the remaining $185(44.0 \%)$. In the practice of $\mathrm{EBF}$, there was no statistically significant difference $(\mathrm{p}$ $=0.443$ ) between mothers who had tertiary education $(137 / 205,66.8 \%)$ and the less educated ones $(136 / 215,63.3 \%)$; similarly, there was no significant difference $(p=0.810)$ between those from high $(66 / 100,66.0 \%)$ and low social class (207/320, 64.7\%).
The weights of the 420 children ranged from 5.7 to $14.0 \mathrm{~kg}$, with a mean of $9.0 \pm 1.6 \mathrm{~kg}$, while their lengths ranged from 62.5 to $92.0 \mathrm{~cm}$, with a mean of $75.0 \pm 5.7 \mathrm{~cm}$. Fifty-six $(13.3 \%)$ of them were underweight, $46(11.0 \%)$ were stunted and 61 (14.5\%) had wasting (Table II).

A total of $103(24.5 \%)$ children had at least one form of malnutrition; 8 of these 103 (7.8\%) children had a combination of all three nutritional abnormalities, while 44 (10.5\%) had a combination of any two abnormalities. Table II shows the nutritional parameters of the children in relation to age. There was no statistically significant difference in the prevalence of underweight $(p=0.882)$, stunting $(p=0.241)$ or wasting $(p=0.186)$ across the age-groups.

The relationship between socio-demographic characteristics and undernutrition is depicted in Table III. 
Table II: Nutritional parameters of the children in relation to age

\begin{tabular}{lllll}
\hline Nutritional status & \multicolumn{3}{c}{ Age Groups } & $\begin{array}{l}\text { Total } \\
\boldsymbol{n}(\%)\end{array}$ \\
\hline & $\mathbf{6 - 1 2}$ months & $\begin{array}{l}\mathbf{1 3 - 1 8} \\
\text { months }\end{array}$ & $\begin{array}{l}\mathbf{1 1 8} \\
\text { months }\end{array}$ \\
& $\mathrm{n}(\%)$ & $\mathrm{n}(\%)$ & $\mathrm{n}(\%)$ & \\
Underweight & $26(46.4)$ & $20(35.7)$ & $10(17.9)$ & $56(100.0)$ \\
Stunting & $18(39.1)$ & $17(37.0)$ & $11(23.9)$ & $46(100.0)$ \\
Wasting & $35(57.4)$ & $19(31.1)$ & $7(11.5)$ & $61(100.0)$ \\
Undernourished & $52(50.5)$ & $35(34.0)$ & $16(15.5)$ & $103(100.0)$ \\
\hline
\end{tabular}

Table III: Relationship between socio-demographic characteristics and distribution of undernutrition

\begin{tabular}{|c|c|c|c|c|}
\hline \multicolumn{2}{|l|}{ Characteristics } & \multicolumn{2}{|c|}{ Undernutrition } & \multirow[t]{2}{*}{ Statistics } \\
\hline & & $\begin{array}{l}\text { Yes } \\
\text { n (\%) }\end{array}$ & $\begin{array}{l}\text { No } \\
\mathrm{n}(\%)\end{array}$ & \\
\hline \multirow[t]{2}{*}{ Age Group } & 6-12 months $(\mathrm{n}=196)$ & $52(26.5)$ & $144(73.5)$ & $\chi^{2}=0.80$ \\
\hline & $13-24$ months $(n=224)$ & $51(22.8)$ & $173(77.2)$ & $p=0.371$ \\
\hline \multirow[t]{2}{*}{ Sex } & Male $(\mathrm{n}=248)$ & $67(27.0)$ & $181(73.0)$ & $x^{2}=2.03$ \\
\hline & Female $(n=172)$ & $36(20.9)$ & $136(79.1)$ & $p=0.154$ \\
\hline \multirow{2}{*}{$\begin{array}{l}\text { Mother's level of } \\
\text { education }\end{array}$} & Below tertiary $(\mathrm{n}=$ & $63(29.3)$ & $152(70.7)$ & $X^{2}=5.43$ \\
\hline & Tertiary $(n=205)$ & $40(19.5)$ & $165(80.5)$ & $p=0.020$ \\
\hline \multirow[t]{2}{*}{ Social class } & Low $(\mathrm{n}=320)$ & $88(27.5)$ & $232(72.5)$ & $x^{2}=6.43$ \\
\hline & High $(n=100)$ & $15(15.0)$ & $85(85.0)$ & $p=0.011$ \\
\hline
\end{tabular}

Undernutrition had no significant relationship with age $(p=0.371)$ or sex $(p=0.154)$. Children whose mothers had tertiary level of education had a significantly lower prevalence of undernutrition, compared with those whose mothers were less educated $(p=0.020)$. Similarly, undernutrition was less prevalent among children from high social class, compared to those from low social class $(p=0.011)$.

A significantly lower proportion of children who had EBF for six months were undernourished, compared to those who had EBF for shorter periods $(21.2 \%$ versus $30.6 \%$; $=0.033)$. The nutritional parameters significantly associated with lack of EBF were underweight $(p=0.026)$ and wasting $(p=0.026)$, as shown in Table IV.
The prevalence of undernutrition did not differ significantly between children who were breastfed for a total duration of $\leq 12$ months and those who were breastfed for $>12$ months $(26.8 \%$ vs. $21.6 \%$, respectively; $\mathrm{p}=0.220$ ).

On logistic regression analysis, lack of EBF had a significant independent association with undernutrition $(\mathrm{OR}=1.62,95 \% \mathrm{CI}=1.02-2.57$, $\mathrm{p}$ $=0.039$ ), while maternal educational status and social class did not, as shown in Table V. Children who had EBF for less than six months were 1.6 times more likely to be undernourished than those who had EBF for six months $(p=0.039)$. 
Table IV: Bivariate analysis of the relationship between breastfeeding and nutritional status

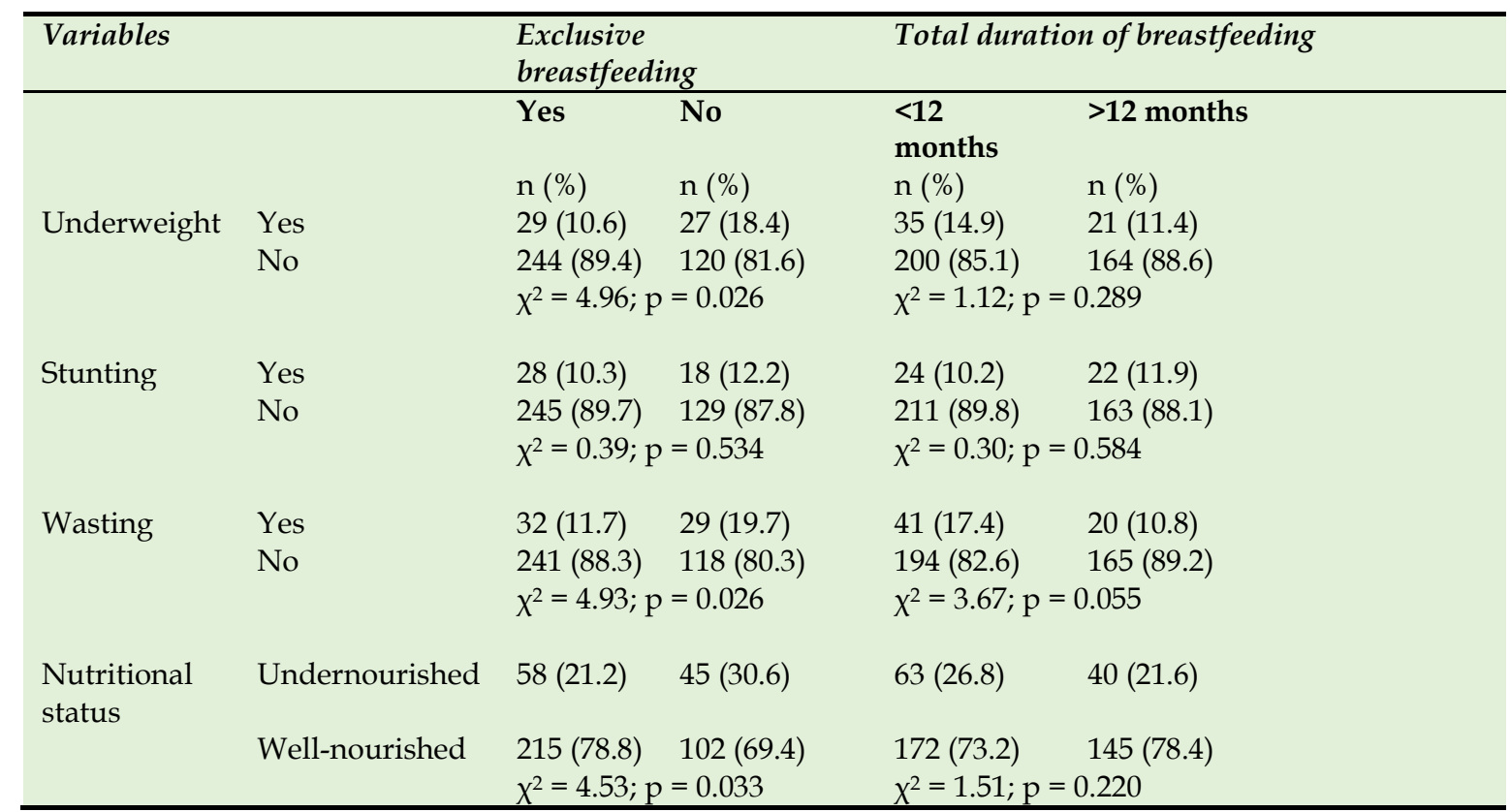

Table V: Logistic regression analysis of factors independently associated with undernutrition

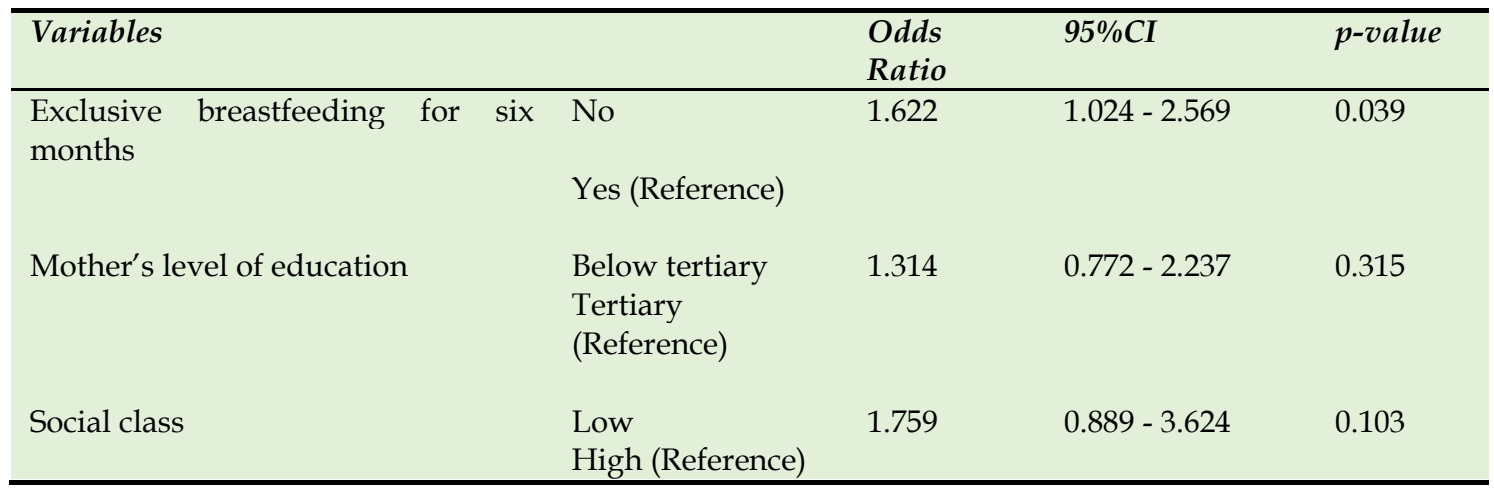

\section{Discussion}

Despite its several benefits, low rates of exclusive breastfeeding (EBF) have been reported in various parts of Nigeria. The Nigeria Demographic and Health Survey (NDHS 2018), [7] reported that about $29 \%$ of Nigerian children below the age of six months were being exclusively breastfed. However, the EBF rate in the present study (65\%) was much higher. Variations in the EBF rates across different states of the country and geo-political zones within the country may partly account for this wide disparity since the value reported in the NDHS was an average and was not classified according to geo-political zones.

About two-thirds of the children in the present study had EBF for six months. This is slightly lower than the EBF rate previously reported by Onayade et al. ${ }^{[20]}$ (76.5\% by six months; the year 2004) in Ile-Ife, Osun State, but much higher than that reported by Ogunlesi et al. [21] $(21.4 \%$ of children studied had EBF for six months) in Ilesa 
about a decade before the present study. The finding in the present study is also higher than the EBF rates reported by Lawoyin et al. [22] in Ibadan, Oyo State (23.4\%; the year 2001), Akodu et al. [23] in Lagos State (3.6\%; the year 2014), and Ukegbu et al. [24] in Anambra State (37.3\%; the year 2011). While Onayade et al. ${ }^{[20]}$ and Ukegbu et al, [24] recruited their subjects as neonates and followed them up until six months to assess the practice of EBF, the other three studies ${ }^{[21-23]}$ were cross-sectional studies in which information about EBF was obtained from the mothers of children younger than two years, as was done in the present study.

The wide difference in the EBF rates between the present study and the study ${ }^{[21]}$ carried out earlier in the same centre may suggest that the rate of EBF among mothers in Ilesa has improved over the years; however, the inclusion of infants below the age of six months in the previous study may give a lower EBF rate, as those infants were yet to complete the six months defining EBF. The higher rates of EBF in the present study and the study carried out by Onayade et al.[20] as compared to other studies, may be related to the relatively less urban nature of the study locations (Ilesa and Ile-Ife, respectively), suggesting less stress on mothers, and resulting in greater feasibility of EBF. Previous studies have also reported higher breastfeeding rates among mothers living in rural areas, compared with urban areas. ${ }^{7,25]}$ In addition, socio-cultural beliefs and practices, such as traditional newborn care practices and traditional rites, may contribute to differences in breastfeeding practices across rural and urban settings.[26]

The prevalence rates of underweight and stunting in the present study $(13.3 \%$ and $11.0 \%$, respectively) were lower than the national averages reported in the NDHS (22\% and 37\%, respectively), ${ }^{[7]}$ while the prevalence rate of wasting was higher in the present study $(14.5 \%$ versus $7 \%$ ). However, the NDHS recounted that the prevalence rates of these nutritional abnormalities were highest in the North East and North West zones of the country and lowest in the Southern zones, which includes the location of the present study. Furthermore, the national figures were among under-five children, while the present study was limited to children two years and below. These variations may account for the observed disparities. Undernutrition was less prevalent in the present study than in a recent report by Oluwafemi et al. [27] in Akure, Ondo State where $18.5 \%, 15.9 \%$ and $20.8 \%$ of under-five children were underweight, stunted and wasted, respectively. The prevalence rate of wasting in the present study was similar to the $14.2 \%$ previously reported by Babatunde et al. ${ }^{[28]}$ in Kwara State; the study, ${ }^{[28]}$ however, reported higher prevalence rates of underweight $(22.0 \%)$ and stunting $(23.6 \%)$ than in the present study. The variations may be partly due to the inclusion of children older than two years in the earlier studies.

In the present study, the prevalence rate of undernutrition was lower among children from high social class and those whose mothers had tertiary level of education. This is in agreement with previous reports. [7, 29-32] Igbokwe et al.[29] observed a significantly lower prevalence of undernutrition among South-Eastern Nigerian children whose mothers had tertiary education. Similar findings have also been reported in other countries, including Ghana, Malawi, Tanzania and Zimbabwe.[30,31] The lower prevalence of undernutrition among children of well-educated mothers in the present study could not be directly attributed to better EBF practice since there was no significant difference in the practice of EBF between such mothers and the less educated ones. The improved nutritional status among children of well-educated mothers may be related to a better knowledge of healthy diet and ability to make the right food choices, as well as higher chances of being gainfully employed so that they can afford these food items. ${ }^{[32]}$ The 
positive influence of higher socio-economic status on the nutritional status of children had also been earlier reported. [7, 29, 32] Families from high socio-economic class are likely to have higher income and can afford healthy food items, some of which may be expensive. [32]

Children who had EBF for six months had a significantly lower prevalence of undernutrition in the present study. This affirms the beneficial effect of breastfeeding on the prevention of undernutrition in young children. $\left.{ }^{1}, 20,33\right]$ Precisely, underweight and wasting were the nutritional abnormalities found to be significantly associated with failure to practice EBF for six months in the present study. Kuchenbecker et al. ${ }^{[14]}$ found that infants below the age of six months who were exclusively breastfed (receiving only breastmilk till the time of the study) were less likely to be underweight and/or stunted, but found no significant difference in the risk for wasting between the EBF group and their non-EBF peers. Similarly, Ahmed et al.[15] reported that children who did not have EBF for six months were at a significantly higher risk of underweight or stunting, but not wasting. However, Muchina and Waithaka ${ }^{[16]}$ reported that EBF for six months was protective against underweight, but found no significant association between EBF and stunting or wasting. Okolo et al. [17] observed underweight and stunting only in infants whose mothers did not breastfeed optimally. Although the risk of being underweight was uniformly reduced by EBF in all these studies, findings concerning stunting and wasting were conflicting. These differences may be related to the fact that the studies were carried out in different populations who have different staple foods and diets.

Limitation (s) of the study

The complementary feeds and weaning diet of the children, which can influence their growth and nutritional status, was not assessed in this study. Moreover, since the study design was cross-sectional, causal relationships between EBF and nutritional status could not be established.

\section{Conclusion}

Exclusive breastfeeding (EBF) significantly reduces the risk of undernutrition among young children. Mothers should be encouraged to exclusively breastfeed their infants for the first six months of life to reduce the burden of undernutrition, and subsequently reduce childhood deaths in developing countries.

Authors' Contributions: AOO, OOO, OSB and AMA contributed substantially to the concept and design of the study and were involved in data collection. Data analysis was performed by AOO, SKJ and AAO. The manuscript was drafted by AOO, while OOO, OSB, $\mathrm{SKJ}$ and AAO reviewed the manuscript for sound intellectual contents. The final version of the manuscript was approved by all the authors.

Conflicts of interest: None.

Funding: Self-funded.

Publication History Submitted 09 April 2021; Accepted 09 May 2021.

\section{References}

1. WHO/UNICEF. Global strategy for infant and young child feeding. Geneva: World Health Organization; 2003. URL: https://apps.who.int/iris/bitstream/handle /10665/42590/9241562218.pdf/jsessionid $=0$ 372B1AB1BCA172CED40BA3435FBA3CC?se quence $=1$

2. Lamberti LM, Fischer-Walker CL, Noiman A, Victora C, Black RE. Breastfeeding and the risk for diarrhea morbidity and mortality. BMC Public Health 2011; 11: S15-27. https://doi.org/10.1186/1471-2458-11-S3$\underline{\text { Ss15 }}$

3. Hanieh S, Ha TT, Simpson JA, Thuy TT, Khuong NC, Thoang DD, et al. Exclusive 
breastfeeding in early infancy reduces the risk of inpatient admission for diarrhea and suspected pneumonia in rural Vietnam: a prospective cohort study. BMC Public Health 2015; 15: 1166. https://doi.org/10.1186/s12889-015-2431-9

4. Story L, Parish T. Breastfeeding helps prevent two major infant illnesses. Internet J Allied Health Sci Pract 2008; 6: 1-5.

5. Bowatte G, Tham R, Allen K, Tan D, Lau M, Dai $\mathrm{X}$, et al. Breastfeeding and childhood acute otitis media: a systematic review and meta-analysis. Acta Paediatr 2015; 104: 85-95. https://doi.org/10.1111/apa.13151

6. WHO/UNICEF. Indicators for assessing infant and young child feeding practices: Part 1; Definitions. Geneva: World Health Organization; $2008 . \quad$ URL: https://apps.who.int/iris/bitstream/handle /10665/43895/9789241596664_eng.pdf?sequ ence $=1$

7. National Population Commission (NPC) [Nigeria] and ICF. Nigeria Demographic and Health Survey (NDHS) 2018. Abuja, Nigeria, and Rockville, Maryland, USA: NPC and ICF; 2019.

URL: https://www.dhsprogram.com/pubs/pdf/ FR359/FR359.pdf

8. Ella RE, Ndep AO, Akpan MI. Factors affecting exclusive breastfeeding practice in rural communities of Cross River State, Nigeria. Int J Human Soc Sci Edu 2016; 3: 101 $110 . \quad$ https://doi.org/10.20431/2349$\underline{0381.0304012}$

9. Liben ML, Gemechu YB, Adugnew M, Asrade A, Adamie B, Gebremedin E, et al. Factors associated with exclusive breastfeeding practices among mothers in Dubti town, afar regional state, northeast Ethiopia: a community based cross-sectional study. Int Breastfeed J 2016; 11: 4 . https://doi.org/10.1186/s13006-016-0064-y
10. Wanjohi M, Griffiths P, Wekesah F, Muriuki $\mathrm{P}$, Muhia N, Musoke RN, et al. Sociocultural factors influencing breastfeeding practices in two slums in Nairobi, Kenya. Int Breastfeed J 2016; 12. https://doi.org/10.1186/s13006016-0092-7

11. Nangalu R, Pooni PA, Bhargav S, Bains HS. Impact of malnutrition on the pediatric risk of mortality score and outcome in Pediatric Intensive Care Unit. Indian J Crit Care Med 2016; 20: 385-90. https://doi.org/10.4103/0972-5229.186218

12. Caulfield LE, de Onis M, Blössner M, Black RE. Undernutrition as an underlying cause of child deaths associated with diarrhoea, pneumonia, malaria, and measles. Am J Clin Nutr 2004; 80: 193-198. https://doi.org/10.1093/ajen/80.1.193

13. McDonald CM, Olofin I, Flaxman S, Fawzi WW, Spiegelman D, Caulfield LE, et al. The effect of multiple anthropometric deficits on child mortality: a meta-analysis of individual data in 10 prospective studies from developing countries. Am J Clin Nutr 2013; 97:

896-901.

https://doi.org/10.3945/ajen.112.047639

14. Kuchenbecker J, Jordan I, Reinbott A, Herrmann J, Jeremias T, Kennedy G, et al. Exclusive breastfeeding and its effect on growth of Malawian infants: results from a cross-sectional study. Paediatr Int Child Health 2015; 35: 14-23. https://doi.org/10.1179/2046905514Y.00000 $\underline{000134}$

15. Ahmed R, Sultana P, Al-Fuad S, Islam A. Association between breastfeeding practices and nutritional status of children aged 6-24 months in Jessore, Bangladesh. Int J Health Sci Res 2017; 7: 247-251.

16. Muchina EN, Waithaka PM. Relationship between breastfeeding practices and nutritional status of children aged 0-24 months in Nairobi, Kenya. Afr J Food Agric 
Nutr Dev 2010; 10: 2358-2378. https://doi.org/10.4314/ajfand.v10i4.55329

17. Okolo AA, Omoyibo E, Chimah UO. Breastfeeding practices and growth. Niger J Paediatr 2015; 42: 335-339. https://doi.org/10.4314/njp.v42i4.10

18. Oyedeji GA. Socioeconomic and cultural background of hospitalized children in Ilesa. Niger J Paediatr 1985; 13: 111-8.

19. WHO. WHO child growth standards; Methods and development: Length/heightfor-age, weight-for-age, weight-for-length, weight-for-height and body mass index-forage. Geneva: World Health Organization; 2006.

URL: https://www.who.int/childgrowth/standar ds/Technical_report.pdf

20. Onayade AA, Abiona TC, Abayomi IO, Makanjuola RO. The first six-month growth and illness of exclusively and non-exclusively breastfed infants in Nigeria. East Afr Med J 2004; 81: 146-153. https://doi.org/10.4314/eamj.v8i3.9145

21. Ogunlesi T, Dedeke O, Okeniyi J, Oyedeji G. Infant and toddler feeding practices in the Baby-Friendly Initiative (BFI) era in Ilesa, Nigeria. Internet J Nutr Wellness 2004; 1 (2).

22. Lawoyin TO, Olawuyi JF, Onadeko MO. Factors associated with exclusive breastfeeding in Ibadan, Nigeria. J Hum Lact 2001; $\quad$ 321-325. https://doi.org/10.1177/08903344010170040 $\underline{6}$

23. Akodu SO, Njokanma OF, Disu EA, Anga AL, Kehinde OA. Exclusive breastfeeding practices among women attending a private health facility in Lagos, Nigeria. Niger J Paediatr 2014; 41: 345-349. https://doi.org/10.4314/njp.v41i4.11

24. Ukegbu AU, Ukegbu PO, Onyeonoro UU, Ubajaka CF. Determinants of breastfeeding patterns among mothers in Anambra State,
Nigeria. South Afr J Child Health 2011; 5: 112116.

25. Balogun MR, Okpalugo OA, Ogunyemi AO, Sekoni AO. Knowledge, attitude, and practice of breastfeeding: A comparative study of mothers in urban and rural communities of Lagos, Southwest Nigeria. Niger Med J 2017; 58:

123-130.

https://doi.org/10.4103/nmj.NMI_289_16

26. Joseph FI, Earland J. A qualitative exploration of the sociocultural determinants of exclusive breastfeeding practices among rural mothers, North-West Nigeria. Int Breastfeed J 2019; 14: 38. https://doi.org/10.1186/s13006-019$\underline{0231-\mathrm{Z}}$

27. Oluwafemi RO, Alonge AO, Abiodun MT. Malnutrition survey among children aged one to five years in an outpatient setting. Ann Health Res 2020; 6: 370-381. https://doi.org/10.30442/ahr.0604-02-100

28. Babatunde RO, Olagunju FI, Fakayode SB, Sola-Ojo FE. Prevalence and determinants of malnutrition among under-five children of farming households in Kwara State, Nigeria. J Agric Sci 2011; 3: 173-181. https://doi.org/10.5539/jas.v3n3p173

29. Igbokwe O, Adimorah G, Ikefuna A, Ibeziako $\mathrm{N}$, Ubesie A, Ekeh C, et al. Socio-demographic determinants of malnutrition among primary school-aged children in Enugu, Nigeria. Pan Afr Med J 2017; 28: 248. https://doi.org/10.11604/pamj.2017.28.248. $\underline{13171}$

30. Aguree S, Soyiri IN, Ziem JB. Maternal educational attainment is associated with child nutrition status in Northern Ghana. Act Sci Nutr Health 2020; 4: 91-98.

31. Makoka D. The Impact of Maternal Education on Child Nutrition: Evidence from Malawi, Tanzania and Zimbabwe. DHS Working Papers no. 84. ICF International; Calverton, MD: $2013 . \quad$ URL: 
https://dhsprogram.com/pubs/pdf/WP84 /WP84.pdf

32. Ndukwu CI, Egbuonu I, Ulasi TO, Ebenebe JC. Determinants of undernutrition among primary school children residing in slum areas of a Nigerian city. Niger J Clin Pract 2013; 16 : 178-183. https://doi.org/10.4103/1119-3077.110142
33. Lawan UM, Amole GT, Jahum MG, Sani A. Age-appropriate feeding practices and nutritional status of infants attending child welfare clinic at a teaching hospital in Nigeria. J Family Community Med 2014; 21: 6-12. https://doi.org/10.4103/2230source is adequately cited and credited. 